\title{
ON THE SEXUAL BEHAVIOUR OF THE ITALIAN NEWT, TRITURUS ITALICUS (CAUDATA: SALAMANDRIDAE)
}

\author{
by \\ CRISTINA GIACOMA \\ Dipartimento di Biologia animale, V.A. Albertina 17, 10123 Torino, Italy \\ \& \\ MAX SPARREBOOM \\ Egelantiersgracht 11, 1015 RB Amsterdam, The Netherlands
}

\begin{abstract}
The sexual behaviour of the Italian Newt Triturus italicus is characterized by an extended phase of static display. Tail fanning is the predominant movement during this stage. Shortly before creeping, a flicking tail movement is inserted in the display. Occasionally the male retreats in front of the female before turning to the spermatophore transfer phase. This behaviour is comparable to the retreat display of the $T$. vulgaris-helveticus-montandoni group. The long phase of static display resembles the behaviour of another species, $T$. boscai. In $T$. italicus, behaviours like retreat and tail touch by the female appear to be less stereotyped than in the $T$. vulgaris-helveticus-montandoni group.
\end{abstract}

\section{RÉSUMÉ}

La parade sexuelle du Triton d'Italie Triturus italicus est caractérisée par une longue phase d'exhibition. Les mouvements d'éventail sont prédominants pendant cette phase. Juste avant le rampement du mâle, un mouvement appelé flick est incorporé dans la parade. Quelquefois le mâle se retire devant la femelle avant de procéder à la phase du transfer du spermatophore. Ce comportement est comparable à la parade de retraite du groupe de $T$. vulgaris-helveticus-montandoni. La phase étendue d'exhibition ressemble au comportement d'une autre espèce, $T$. boscai. Chez $T$. italicus, des comportements comme retrait et toucher la queue par la femelle apparaissent moins stéréotypés comme dans le groupe de $T$. vulgaris-helveticusmontandoni.

\section{INTRODUCTION}

The general pattern of courtship behaviour in the salamandrid genus Triturus, from the initial male display actions up to and including the sperm transfer, is now known, but detailed analyses of the courtship sequence are not yet available for every species. Since the early seventies, some species have been studied in detail (Arnold, 1972; Halliday, 1974). The work done on the sexual behaviour of Triturus vulgaris (Linnaeus, 1758) has formed an important point of reference for further systematic studies of newt courtship.

In the present paper, the sexual behaviour of the Italian Newt, Triturus italicus (Peracca, 1898), is described and integrated with the knowledge of the behaviour of the other Triturus species. [Preliminary notes appeared by Giacoma (1985) and Sparreboom (1986)]. The courtship of the bigger species $T$. cristatus (Laurenti, 1768), T. marmoratus (Latreille, 1800) and of $T$. vittatus (Gray, 1835) diverges considerably from that of the small species (Halliday, 1977; Sparreboom, 1986) and can be used for comparison to only a certain extent. $T$. boscai (Lataste, 1879) is similar to $T$. italicus in general appearance (no extreme sexual dimorphism) and behaviour. For comparison with $T$ italicus some preliminary data of the courtship of this species are available (Krefft, 1937; Rafiński \& Czaja, 1983, 1984; Sparreboom, pers. observations).

The present authors studied the behaviour of T. italicus independently from each other, C. G. from 1982, M. S. from 1984 onwards. Our data proved to be largely in agreement. The quantifications were mainly calculated from C. G.'s 
data, whereas the qualitative description is based on the observations by both authors. The comparison with the behaviour of $T$. boscai is based on observations by M. S.

\section{MATERIAL AND METHODS}

The newts were collected from several ponds in Calabria in southern Italy (by C. G.) and from ponds near Benevento and Vinchiaturo in central Italy (M. S.). The Italian Newt is the smallest species of Triturus. The males are on the average a little smaller than the females. In different parts of its range the size varies considerably (Bruno, 1973; Giacoma, Rossi \& Tripepi, in prep.). Compared to the other Triturus species, the sexes of the Italian Newt are not very dimorphic. In both sexes the back is yellow-brownish, the belly and throat orange-yellow, covered with irregularly scattered dark spots. Both sexes may develop a golden blotch behind the eye during the breeding season. Males in breeding condition have gold spots on the flank and have dorsolateral ridges, giving the body roughly a square shape when viewed in a transverse section. The male's tail has a metallic blue shine, its cloaca is larger and more rounded than that of the female. During courtship display, the villi of the cloacal glands are visible in the black aperture of the cloaca of the male. The tail has a low dorsal fin and may end in a short filament.

The sexes were kept separate in aquaria of $40 \times 70 \times 50$ $\mathrm{cm}$, floored with gravel and furnished with different water plants. The water was kept flowing by slowly running tap water (C. G.) or was stagnant (M. S.). Water temperatures ranged from $10^{\circ}$ to $20^{\circ} \mathrm{C}$, following the seasonal temperature cycle. The animals were fed on larvae of Chironomidae, Tubifex and Daphnia. For the observations, one male and one female were put together in a smaller aquarium.

To allow a better comparison with the behaviour of the other Triturus species, the behaviour of $T$. italicus was described from observations of one couple at a time per aquarium. A study of this species' behaviour under natural conditions has revealed that the same repertoire is shown as in the aquarium, but that there are differences in frequency and duration of the different behaviours (Giacoma \& Crusco, 1987). This was, for instance, also found in T. vulgaris (Verrell, 1984).

C. G. spent 135 hours, observing five couples at the same time; 208 encounters were recorded, of which 143 $(69 \%)$ were broken off in an early stage, and $65(31 \%)$ ended with the male turning round and starting to creep ahead of the female. Of these 65 advanced courtships, 26 ( $40 \%$, or $13 \%$ of the total number of sexual encounters) ended with the deposition of one or more spermatophores. M. S. spent 35 hours, observing two couples at a time; 23 encounters were recorded, of which $5(22 \%)$ ended with the deposition of one or more spermatophores. The data were recorded as a spoken commentary on tape, by the use of notebooks, stopwatches, still-, super 8 cine- and video-cameras.

In his description of the sexual behaviour of $T$. vulgaris, Halliday (1974) has defined a number of terms, characteristic of the different elements of the courtship repertoire. As much as possible these terms were also used in our description of the behaviour of $T$. italicus.

\section{RESULTS}

Courtship starts when the male attempts to take up a snout-to-snout position in front of the female. This may be preceded by sniffing at her body. In 4 out of 65 encounters the courtship was preceded by sniffing. Occasionally the female also sniffs at the body of the male. As a first reaction to the male's manoeuvres, the female almost invariably swims or walks away. The male will follow her and continue to jump ahead of her and begin his display. This may be called the orientation phase, similar to that described for T. vulgaris (cf. Halliday, 1974).

When the male's efforts at arresting the female are eventually successful and the female is standing still, the male starts displaying. $\mathrm{He}$ usually takes up a position with his body at an angle between $60^{\circ}$ and $120^{\circ}$ to the body of the female (figs. 1 and 2). He folds back the distal part of his tail and performs a very rapid vibratory movement with it in the direction of the female's snout. During this fanning, both partners have their legs more or less stretched and remain standing in this position almost motionless. Identical to this stage in the courtship of $T$. vulgaris, this phase may be termed the phase of static display.

In the static display phase of $T$. italicus fanning is the predominant movement. The duration of this phase, depending on the internal state of the male and the responsiveness of the female, is between a few seconds and 52 minutes, with a mean duration of $10 \pm 1.1$ minutes (cf. fig. 10). The tail is vibrated at a frequency of 12-16 beats per second. The frequency of beating was counted from movieshots of a few fans, their number too low to permit the computation of variance. Fanning bouts lasted from 2 to 362 seconds. After the first fanning bouts, that were usually short ( 2 to 10 


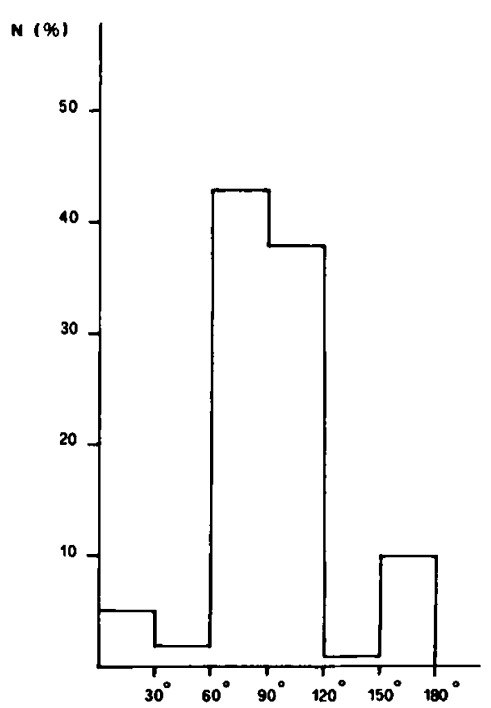

Fig. 1. Width of the angle of the male's position towards the female during static display.

seconds), the fanning periods became longer and formed a continuous process. Of 35 recorded fans, 10 lasted longer than one minute, without a single interruption. The average fanning bout duration was 53 seconds. If one partner changed its position, be it a few millimetres, the other would adjust its position with a little shock, usually by moving the head a little aside, down or upwards. In the course of this fanning display, the partners hardly moved one step and the female leaned a little forward with her legs stretched obliquely backwards.

After the fanning display has proceeded some time, the male may change his behaviour. For the observer, the releasing of an air bubble ("guffing") by the male may indicate the beginning of the next phase. The female may make a little movement or she may remain motionless. The tail beats, up to this moment consisting of a delicate and sustained fanning, become agitated and irregular and of larger amplitude than during fanning. Not just the distal half of the tail is folded back against the flank, but the full length of the tail may be curved back, making fluttering and whirling movements in the direction of the female, occasionally almost touching her snout with the tail tip. This larger amplitude movement implies alternating outward-lashing movements away from the flank and beats with the tail tip against the flank (fig. 3). The tail may then be pulled back into fanning position. In this process the distal half of the tail is not always kept parallel to the male's body as during fanning, but may flutter a little over the male's back. We have termed these "disorderly" tail movements the flick, since this behaviour looks similar to a thus named movement, observed for $T$. boscai by Rafiński (pers. comm.). Flicking bouts last from two to three seconds and are alternated with fanning bouts of different duration. This flick creates a stronger current of water in the direction of the female than the fan and may push the male a little backwards in front of the female. The flick is different from what Halliday has termed the whip in the display behaviour of $T$. vulgaris (Halliday, 1974). The whip is a single vigorous movement, whereas the flick is a complex movement during which the tail makes various fluttering movements and not a single lash. A whip is absent in the behavioural repertoire of $T$. italicus. The flick appears to be mainly shown at the end of the static display, shortly before the male turns to creep.

While performing fan and flick, the male may retreat a few steps in front of the female. While doing this, he changes his position relative to hers, sharpening the angle of the position at which he was fanning her. We consider this as characteristic of what has been termed the retreat display phase in the courtship of $T$. vulgaris-helveticus-montandoni (Halliday, 1977; Pecio \& Rafiński, 1985). Of 16 instances of retreat display recorded on video, the duration varied from 2 to 13 seconds, with an average duration of 6 seconds. In the courtship of $T$. italicus, a retreat display is not invariably inserted.

After retreating, accompanied by fan and flick, or just after performing fan and flick (without retreating), the male turns round. He walks in front of the female in a quick, dancing manner, his body kept close to the ground and his tail making rapid undulating movements (fig. 4). A similar movement in T. vulgaris has 

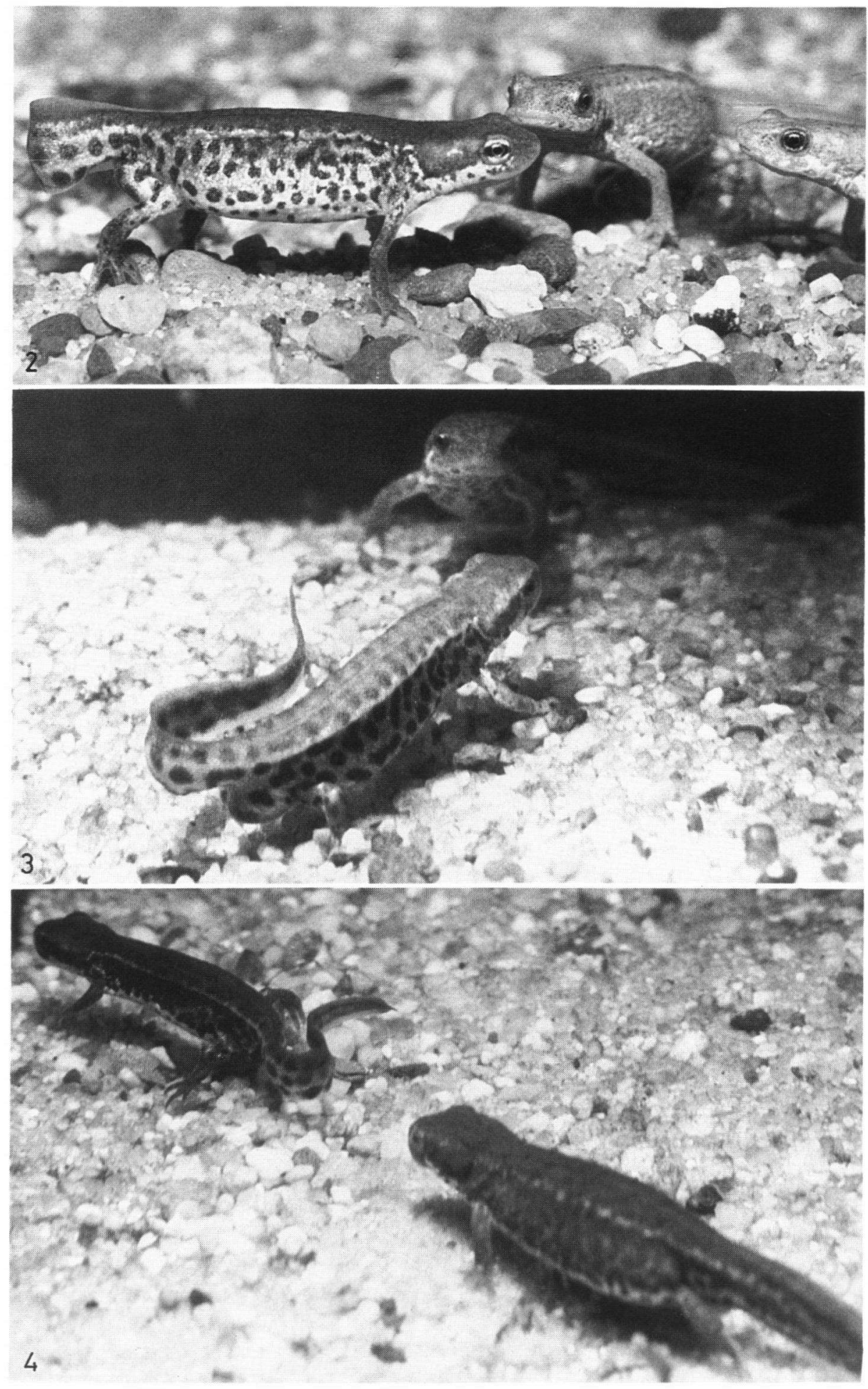

Fig. 2. Male Triturus italicus (left) fanning.

Fig. 3. Male Triturus italicus making the flick with the tail during retreat display

Fig. 4. Male Triturus italicus creeping ahead of the female. 

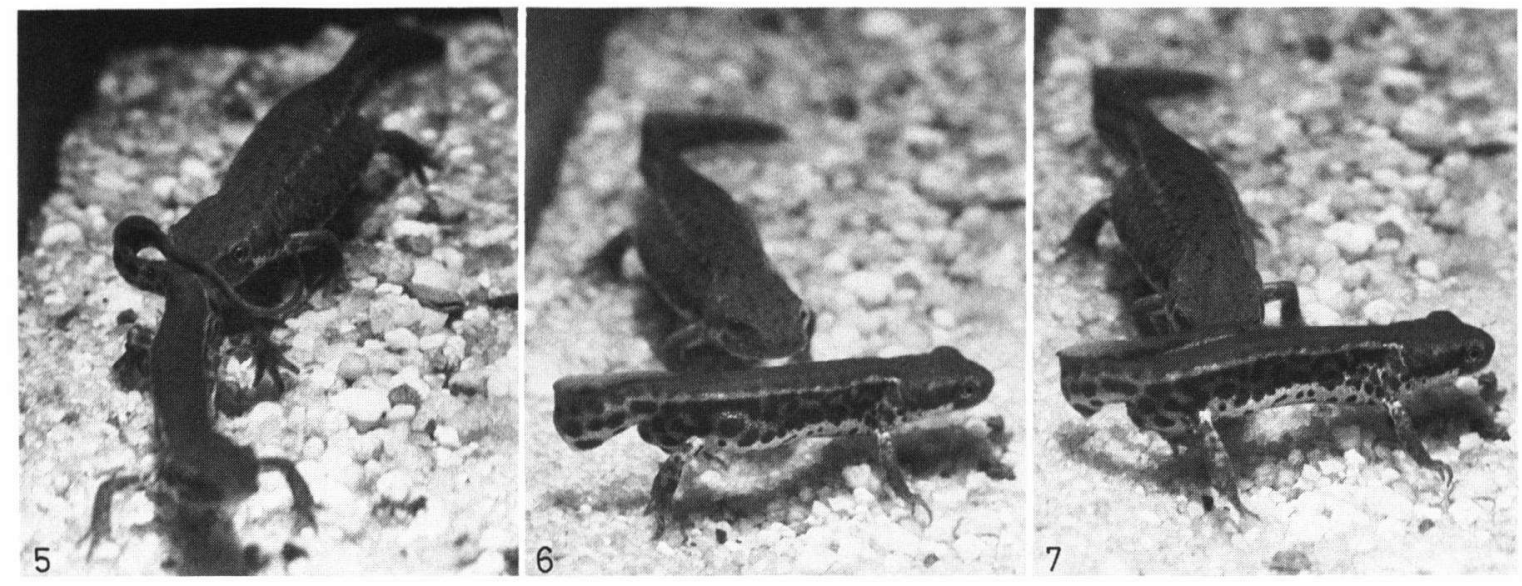

Fig. 5. Male T. italicus during spermatophore deposition. The tail is folded and raised slightly. The female follows closely, her snout at his tail.

Fig. 6. After spermatophore deposition the male turns side-on to the female. The female makes a few steps forward. Fig. 7. The male pushes back the female, bending his body towards her snout and flexing his tail away from his flank against her snout.

been termed the creep (cf. Halliday, 1974). The female now follows the male, her cloaca slightly protruding. While following the male, she may or may not touch his tail with her snout (fig. 5).

Of the 65 occurrences of creep behaviour recorded of the male, only $26(40 \%)$ ended with a sperm deposition. When the male has crept ahead a few centimetres, he stands still and may show a shivering movement of the hindbody and tail. The tail is raised a little and undulating waves pass along it from base to tip. This behaviour is similar to the "quiver" described for T. vulgaris (Halliday, 1974) and is a preliminary to sperm deposition. During spermatophore deposition the tail is slightly raised and flexed harmonica-wise.

After sperm deposition the male creeps on a few centimetres and then turns $90^{\circ}$, taking up a position perpendicular to the female (fig. 6) and thereby stopping her. This position has been termed "brake" for T. vulgaris (Halliday, 1974). From this position in front of the female, the male executes different types of tail movements. He keeps his tail flexed against his flank, making irregular undulating movements with it. These are alternated with slow, wormlike movements with the tail tip, the tail curved back and the tip raised obliquely upwards (fig. 8).

These wormlike movements of the tail tip we have termed "distal lure", on the basis of the description of a similar movement in $T$. helveticus by Wambreuse \& Bels (1984), who termed it "ondulation distale". (The English term "distal wave" proposed by Wambreuse \& Bels (1984) is avoided here as it might create confusion with the "wave". "Wave" has been described as a totally different visual display posture in the behaviour of $T$. vulgaris (Halliday, 1974, 1977)). In 4 of 12 instances where distal lure was performed after a creep-on and brake behaviour, the female came near and touched the male's tail, but we have not enough data to make statements on the influence of this behaviour on the female. The distal lure may rarely also be shown during the static display phase, for instance after a prolonged period of fanning.

There is yet another behaviour that is occasionally shown before the spermatophore transfer phase: The male turns away from the female he has been fanning to, as if starting to creep. Instead he raises his tail and straightens it, holding it up in a position almost perpen- 

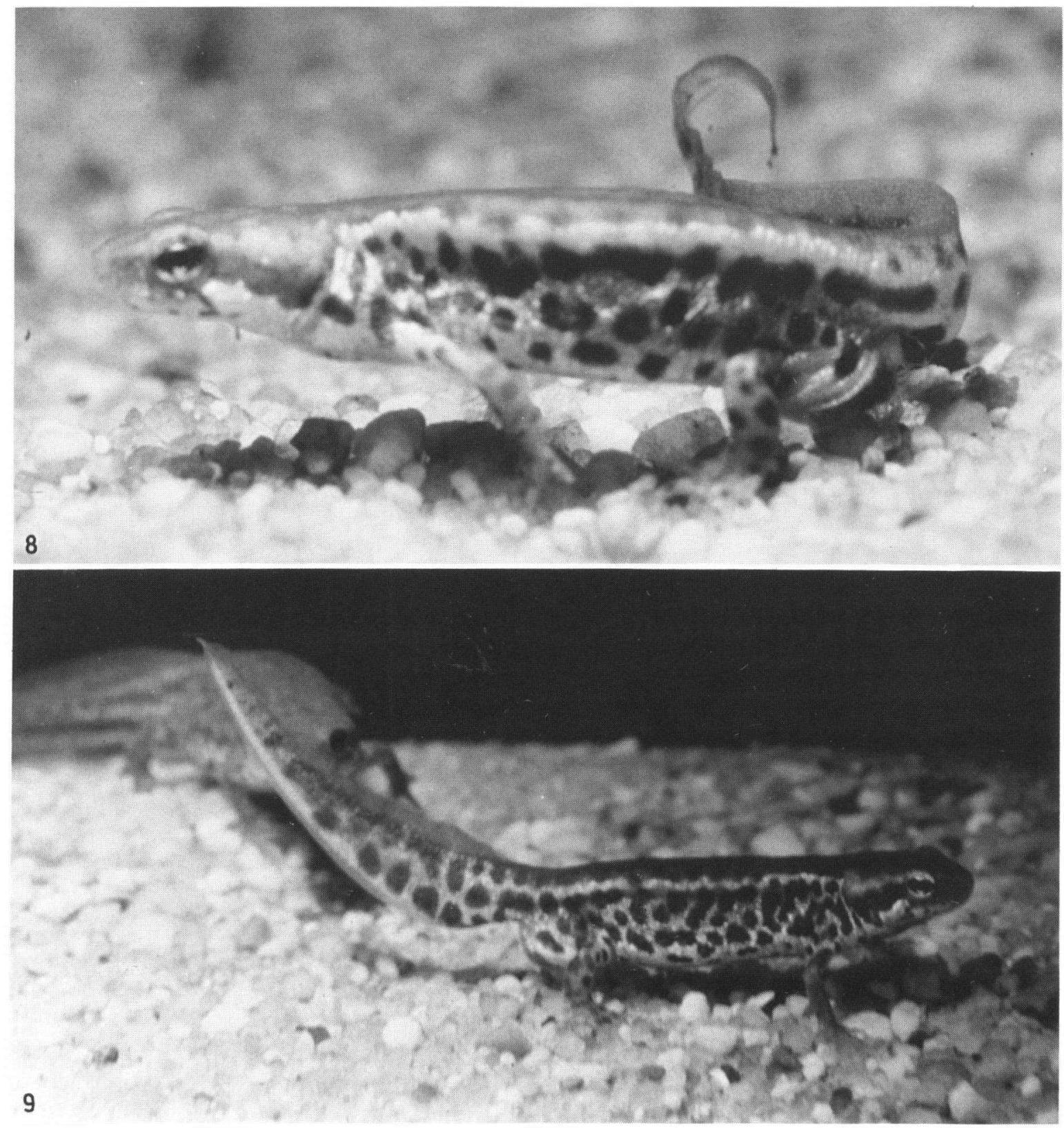

Fig. 8. The male executes the "distal lure", with tail flexed and tail tip slightly raised over the back, making wormlike movements.

Fig. 9. The male performs "luring", with the tail straightened and held up, the tail tip making little undulating movements.

dicular to his body. The tail tip or the distal half of the tail may make a wormlike undulation (fig. 9). This posture, here simply referred to with the term "lure", may be assumed after a period of "unsuccessful" fanning. On several occasions the female has been observed to react to this behaviour. She approached from a distance of several body lengths and snapped at the slowly moving tail tip. In such a case a male would react by creeping or reverting to fanning. So this behaviour appears to have some visual or "luring" function but can presently not be 
quantified in a satisfactory manner. It looks identical to the posture described for $T$. boscai (Krefft, 1937: “Anglerstellung"; Rafiński \& Czaja, 1983: "luring").

The final stage of a mating sequence starts when the male has deposited a spermatophore and has taken up the side-on position in front of the female. The female now pushes her snout against the male's tail. On several occasions, the male could be observed pushing her 1 to 2 cm backwards with outward slapping movements of his bent tail and with the hindpart of his body (fig. 7). This movement was repeated several times and appeared to be identical to the so-called "push-back" manoeuvre as described for $T$. vulgaris (Halliday, 1974). By this manoeuvre the female is moved forward and backward at the same spot, her cloaca rubbing over that part of the substrate where the spermatophore was deposited. When the sperm comes into contact with the female's cloaca and adheres to it, we consider the sequence successfully completed. In 12 of $26(46 \%)$ observed sperm depositions the sperm was picked up by the female.

TABLE I

Catalogue of male behaviours.

\begin{tabular}{|c|c|}
\hline fan & $\begin{array}{l}\text { vibration of distal part of tail during static } \\
\text { display (fig. 2). }\end{array}$ \\
\hline flick & $\begin{array}{l}\text { fluttering irregular tail movement at the end } \\
\text { of static display (fig. 3). }\end{array}$ \\
\hline $\begin{array}{l}\text { retreat } \\
\text { display }\end{array}$ & $\begin{array}{l}\text { stepping back in front of female, while per- } \\
\text { forming fan and flick (fig. } 3 \text { ). }\end{array}$ \\
\hline distal lure & $\begin{array}{l}\text { slow wormlike movement with tail bent, } \\
\text { performed (1) after sperm deposition or (2) } \\
\text { after unsuccessful fanning (fig. } 8 \text { ). }\end{array}$ \\
\hline lure & $\begin{array}{l}\text { holding up stretched tail in vertical position, } \\
\text { the tail tip making wormlike movements; } \\
\text { performed after unsuccessful fanning (fig. 9). }\end{array}$ \\
\hline creep & $\begin{array}{l}\text { rapid walk in front of female, preceding } \\
\text { quiver and sperm deposition (fig. 4). }\end{array}$ \\
\hline quiver & $\begin{array}{l}\text { undulation passing along body and tail, } \\
\text { immediately preceding spermatophore de- } \\
\text { position. }\end{array}$ \\
\hline $\begin{array}{l}\text { sperm de- } \\
\text { position }\end{array}$ & $\begin{array}{l}\text { plying tail harmonica-wise and deposition of } \\
\text { spermatophore in front of female (fig. } 5 \text { ). }\end{array}$ \\
\hline brake & $\begin{array}{l}\text { taking up a side-on position to the female, } \\
\text { after sperm deposition (fig. } 6 \text { ). }\end{array}$ \\
\hline push back & $\begin{array}{l}\text { pushing back the following female from } \\
\text { brake position (fig. } 7 \text { ). }\end{array}$ \\
\hline
\end{tabular}

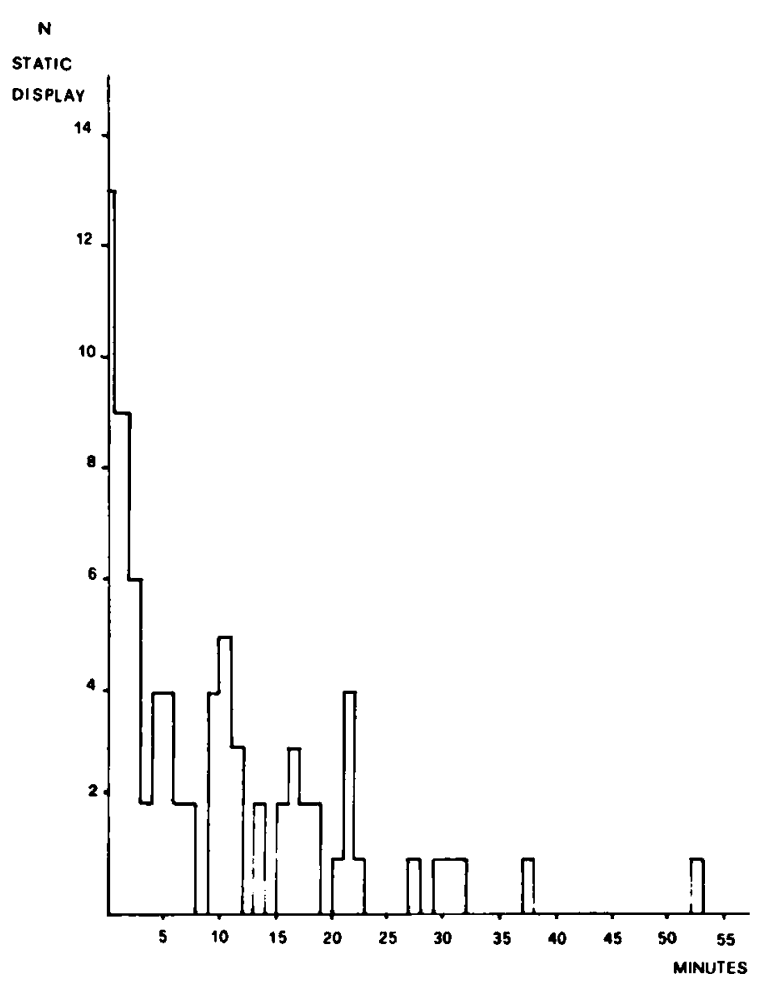

Fig. 10. Frequency distribution of static display duration in complete courtship sequences.

\section{TEMPORAL PATTERNING OF MALE DISPLAY}

For a comparison of the sequential patterning of the behaviour of $T$. italicus with that of other Triturus species, we extracted all first-order transitions between male display acts together with the female behaviour from the observational data and accumulated these into three different transition matrices. One matrix summarizes the results obtained by the analysis of 39 courtships ending with a creep, not followed by spermatophore deposition. The second matrix summarizes the results of 14 courtships that led to the deposition of a spermatophore. The third represents the 12 sequences that ended with a successful sperm pick-up. The arrangement of the display from left to right reflects the general order in which the acts occur, the arrow indicating the main direction. The percentages of the frequencies of the various transitions were calculated to evaluate 
the probability of each transition. The transitions with a frequency higher than $9 \%$ were illustrated (figs. $11 \mathrm{~A}-\mathrm{C}$ ).

During courtships without the deposition of a spermatophore, the female often moved away over some distance during the fanning display of the male. Although transitions in both directions were observed, the overall trend of courtships with successful sperm pick-up is towards the spermatophore deposition phase. Besides that, we frequently recorded the transition from fan to creep ( $31 \%$ of the recorded transitions), a type of short circuit courtship that may also be shown by other species (Malacarne et al., 1983). This short circuit sequence is less frequent in the complete courtships (figs. $11 \mathrm{~B}$ \& C).

The transition from fan to (fan and) flick seems to be a critical point during the courtship, related to a higher probability of spermatophore deposition. The frequency ranges from $27 \%$ in incomplete courtships to $55 \%$ in complete courtships and $71 \%$ in courtship sequences with successful sperm transfer. It would be reasonable to expect that a male will turn to retreat display or (fan and) flick in response to a positive reaction of the female. However, in 58 of 65 courtship sequences, no particular female behaviour was recorded, whereas a slight female approach was seen in only five cases. It is unclear to us what signals the male that the female is ready to follow him and pick up the sperm. Our observations suggest that the immobility of the female may facilitate all transitions towards the final stages of courtship.

In the incomplete courtships, fan, flick and creep are often followed by little movements of the female or by her moving away, for instance for a breathing ascent. In the more successful sequences, there is a more or less regular order in transitions from fan to (fan and) flick and from (fan and) flick to creep. In completely successful courtships fan is followed by (fan and) flick $(71 \%)$, (fan and) flick is mainly followed by creep $(92 \%)$ and creep by spermatophore deposition (94\%); finally the female follows the male $(44 \%)$ and picks up the spermatophore.
Diagram 11c shows that a female approach may or may not anticipate sperm deposition.

At present, only few data are available on sperm pick-up success in case of multiple sperm depositions. Of six sequences, involving the deposition of two spermatophores, five of the first spermatophores were picked up by the female and three of the second ones. This might point to a higher pick-up success $(83 \%)$ of the first spermatophore than of the second $(50 \%)$, which is the reverse of what has been found for T. vulgaris-helveticus-montandoni (Halliday, 1977; Pecio \& Rafiński, 1985). More observations are needed to answer this question. After depositing the first spermatophore, the male reverted to fanning in two cases (in one instance followed by flick), while in the other five instances on record he went straight on to a second sperm deposition.

\section{DISCUSSION}

In the courtship of Triturus species the fanning frequency, the body colouration and most likely also the scent are typical of each species and may function as species recognition characters for the females. Although it remains to be investigated to what extent the specific forms of courtship, along with the morphological differences between the species, have evolved as isolating mechanisms, the external features are certainly related to the courtship repertoire in both a quantitative and qualitative manner (cf. Halliday, 1975). The high crest and the bright colours at the bottom of the tail of the nominate race of $T$. vulgaris are brought into prominence during the static display phase, especially by the "wave" and the "whip".

Compared to the nominate race of $T$. vulgaris, waves and whips are far less frequent in the courtship of $T$. helveticus and T. montandoni, whereas in these species tail fanning is a more prominent element of the display (table II). Not only is the frequency of fanning beats higher, this fanning seems to receive enhanced efficiency by the dorsolateral ridges, which channel the water current in the direction of the 

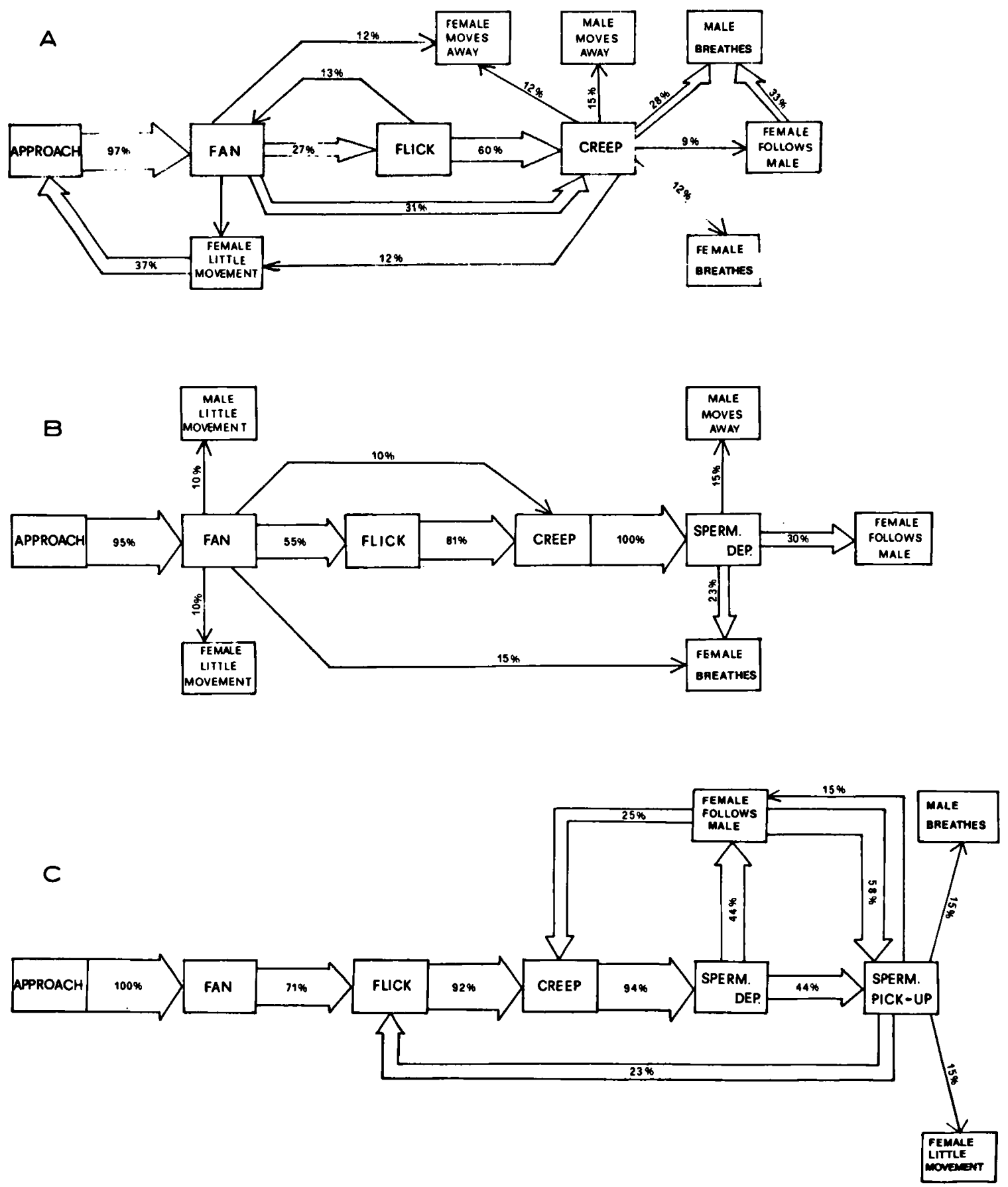

Fig. 11. A, Incomplete courtship sequences broken off before spermatophore deposition; total: 39 sequences. B, Complete courtship sequences ending with spermatophore deposition; total: 14 sequences. C, Complete courtship sequences ending with spermatophore pick-up; total: 12 sequences. 
TABLE II

Comparison of a number of behavioural characters of the courtship of six Triturus species (data from Halliday, 1974, 1975, 1977; Pecio \& Rafiński, 1985; Wambreuse \& Bels, 1984; own observations). Fanning frequency and fanning bout duration are average numbers. These may be variable, depending on male motivation and female responsiveness (see fig. 3 in Wambreuse \& Bels, 1984). $+=$ present, $++=$ prominently present, $-=$ absent, ? = not recorded or unknown. Percentages behind fan represent percentage of time spent fanning as compared with the other courtship movements (wave and whip) during static display.

\begin{tabular}{lllllll}
\hline & T. v. vulgaris & T. helveticus & T. montandoni & T. alpestris & T. boscai & T. italicus \\
\hline fan & $+(20 \%)$ & $+(56 \%)$ & $+(55 \%)$ & $+(100 \%)$ & $+(100 \%)$ & $+(100 \%)$ \\
fanning frequency per second & $5-6$ & 12 & 6.3 & $3-4$ & $?$ & $12-16$ \\
wave & ++ & + & + & - & - & - \\
whip & ++ & + & + & - & - & - \\
retreat display & + & + & + & - & - & + \\
flick & + & - & - & - & + & + \\
$\begin{array}{l}\text { distal lure } \\
\text { luring tail stretched }\end{array}$ & $?$ & + & + & + & + & + \\
$\begin{array}{l}\text { fanning bout duration in } \\
\text { seconds }\end{array}$ & 4.6 & 17.1 & 17.6 & \pm 4 & $?$ & 53 \\
\hline
\end{tabular}

female's snout (Halliday, 1975). On the other hand, the latter species have a much lower crest and less conspicuous colouration. A stronger visual display seems to reduce the importance of tail fanning or, specialized tail fanning compensates for visual display. Should this be a trend, then $T$. italicus could be considered an extreme example. This tail fanning by $T$. italicus is executed from an angle to the female of $60-120^{\circ}$, which is comparable to the angle in T. vulgaris (Halliday, 1974, 1977). T. helveticus fans from an angle of $120-180^{\circ}$ (Van Gelder, 1979) $\left(120^{\circ}\right.$ : Wambreuse \& Bels, 1984). But the frequency of tail beats during fanning is higher in $T$. italicus than in the other species and the time spent fanning, when compared to the other display movements, is much longer than in the courtship of the other species.

This emphasis on an extremely static display behaviour could be considered as being in line with the absence of such strongly dimorphic characters as are found in most other Triturus species. In the courtship of $T$. italicus, the visual stimulus seems to be relatively unimportant and the mechanical or rheotactic one more important.

Besides the fanning display, the male of this species appears to employ another method of persuading the female: Both luring movements (distal lure and luring), if performed after a period of fruitless fanning, are apparently intended to lure an otherwise unreceptive female towards the male. When distal lure is performed after sperm deposition, it is used to direct the female over the sperm by making her proceed a few steps forward. The fact that the female sometimes actually snaps at the male's tail indicates that the moving tail tip effectively functions as a bait-mimic (cf. Rafiński, pers. comm.; Sparreboom, 1986). The effect of these luring movements on sperm pick-up success remains to be investigated.

In its external features $T$. italicus bears some likeness to $T$. boscai. From our unpublished data on the sexual behaviour of $T$. boscai we may conclude that the courtship repertoire is also similar to that of $T$. italicus. $T$. boscai likewise has an extended phase of static display, during which fanning is by far the predominant movement. Whip and wave are absent. Unlike $T$. italicus, this species has no retreat display. But the flick, a movement shown by $T$. italicus mainly in the retreat display phase or at the end of static display, possibly has an equivalent in the flick or the lash of $T$. boscai. (During this lash, the male remains standing in front of the female and curves the full length of his tail back, the tail tip touching the cheek of the 
female. If it is performed at all, it is repeated several times in quick succession).

Another similarity exists in the luring with the tail stretched and held up in a vertical position. As in $T$. italicus, this behaviour is shown after a prolonged period of fanning. In $T$. boscai, this behaviour is even more prominently part of the repertoire. When this fails to draw the female near, the male turns back to her, reverts to sniffing at her headregion and starts fanning again. When she approaches him, he may creep and deposit a spermatophore. This luring behaviour has been termed "Anglerstellung" by Krefft (1937) and "luring” or “flamenco" by Rafiński \& Czaja (1983). This tail movement had not yet been described for the other species. However, similar postures have occasionally been observed in a number of species. $T$. marmoratus males have been observed standing in a position as if starting to creep, holding out the straightened tail up to 30 seconds (pers. observation). A similar posture has occasionally been observed in a $T$. alpestris male (pers. observation) that slowly moved the tail tip while raising the tail in an oblique angle. All these movements may be variants of the same behaviour. Speculating on their function, other explanations are possible besides the mentioned effect of bait-mimic. By raising his tail, the male may display the opened cloaca to the female, or he may produce scent with secretions from his cloaca (a phenomenon described by Gauss, 1961, but not confirmed by other workers).

The tail flick has presently been described as an independent type of behaviour, characteristic of $T$. italicus and may accordingly be considered an apomorphous character. Retreat display is present in $T$. italicus and absent in $T$. boscai. 'The facultative performance of this behaviour in $T$. italicus might be related to a relatively higher level of complexity, involving higher energetic costs. To reduce these costs, the $T$. vulgaris-helveticus-montandoni group may have increased the level of stereotypy, whereas $T$. boscai may have lost this behaviour and placed more emphasis on a "luring" display. The presence of retreat places $T$. italicus closer to the $T$. vulgaris-helveticusmontandoni group, the absence of it places $T$. boscai closer to $T$. alpestris. But since traces of some sort of a retreat display have been observed in $T$. alpestris (Rafiński, pers. comm.) and T. marmoratus (Zuiderwijk, pers.comm.), it is better to be cautious in assigning discriminating value to this character until more detailed data are available.

Like the retreat behaviour, the tail-touch movement by the female appears to be facultative in $T$. italicus and more stereotyped in the $T$. vulgaris-helveticus-montandoni group. Its performance by $T$. italicus is probably related to the degree of sexual motivation of the partners and may further depend on the presence of other individuals in the vicinity (cf. Giacoma \& Crusco, 1987). In T. vulgaris-helveticusmontandoni, the tail touch by the female appears to be a necessary stimulus to the male, as it triggers spermatophore deposition, with only few exceptions (Halliday, 1977; Pecio \& Rafiński, 1985). In $T$. italicus this does not appear to be the case as only 9 of 26 spermatophore depositions $(35 \%)$ were preceded by the female nudging the male's tail. Moreover, in 7 of 35 cases (20\%), the male did not respond to a tail touch by the female by depositing a spermatophore. In $T$. alpestris, $T$. boscai and $T$. cristatus spermatophore deposition without prior tactile stimulus by the female is also on record (Pecio \& Rafiński, 1985).

An immediate transition from a first spermatophore deposition to a second (or a third) one, as we have observed in $T$. italicus, has also been seen in $T$. alpestris (Halliday, 1977; pers. observations) and $T$. boscai (Rafiński \& Czaja, 1983, 1984; pers. observations), whereas $T$. vulgaris-helveticus-montandoni more usually revert either to static display or to retreat display (Halliday, 1977; Pecio \& Rafiński, 1985).

\section{ACKNOWLEDGEMENTS}

Pim Arntzen and Annie Zuiderwijk supplied M. S. with animals. Frits van Leeuwen bred and reared a substantial number of $T$. italicus, enabling M. S. to make his observations. Chris Raxworthy has been kind enough to count the number of tail beats during fanning and to allow us to 
publish his data. The text has greatly benefitted by valuable suggestions of Pim Arntzen, Giorgio Malacarne, Tim Halliday and two anonymous referees. The drawings were finalized by Paola Fratini.

\section{REFERENCES}

ARnold, S. J., 1972. The evolution of courtship behavior in salamanders: 1-570 (Ph.D. dissertation, University of Michigan).

Bruno, S., 1973. Anfibi d'Italia: Caudata (Studi sulla fauna erpetologica italiana - XVII). Natura, Milano, 64 (3-4): 209-450.

Gauss, G. H., 1961. Ein Beitrag zur Kenntnis des Balzverhaltens einheimischer Molche. Z. Tierpsychol., 18: 60-66.

Gelder, J. J. vaN, 1979. Differences in the sexual behaviour of the Smooth Newt Triturus vulgaris and the Palmate Newt Triturus helveticus. In: Y. LeroY ed., Etho-écologie des communications chez les amphibiens. Bull. Soc. zool. Fr., 102 (Suppl. 2) “1977": 23-26.

Giacoma, C., 1985. The courtship of the Italian Newt (T. italicus, Per.). Abstracts of the international ethological conference. Toulouse, 24 August-1 September 1985.

Giacoma, C. N. Crusco, 1987. Courtship and male interferences in the Italian Newt: a field study. Monitore zool. ital. (in press).

Halliday, T. R., 1974. Sexual behaviour of the Smooth Newt, Triturus vulgaris (Urodela, Salamandridae). J. Herpet., 8: 277-292.

,-- 1975 . On the biological significance of certain morphological characters in males of the Smooth Newt Triturus vulgaris and of the Palmate Newt Triturus helveticus (Urodela: Salamandridae). Zool. J. Linn. Soc., 56: 291-300.

- , 1977. The courtship of European newts. An evolutionary perspective. In: D. H. TAYLOR S. I. Guttman eds., Reproductive biology of amphibians: 185-232 (Plenum Press, New York).

Krefft, G., 1937. Zur Fortpflanzungsbiologie von Triturus boscai. Bl. Aquar. Terrarienk., 48: 127-130.

Malacarne, G., T. R. Halliday, P. Verrell * C. R. Cortassa, 1983. Sex roles and behaviour in newts. In: Symposium: Variability and behavioural evolution. Rome, 24-26 November 1983.

Pecio, A. J. Rafiński, 1985. Sexual behaviour of the Montandon's Newt, Triturus montandoni (Boulenger) (Caudata: Salamandridae). AmphibiaReptilia, 6: 11-22.

Rafiński, J. A. Czaja, 1983. Sexual behaviour of the Bosca's Newt, Triturus boscai. In: Abstracts of the second ordinary meeting of the Societas Europaea Herpetologica, León: 45-46.

- $~ \&-1984$. Sexual behaviour of the Bosca's Newt, Triturus boscai. Amphibia-Reptilia, 5: 197.

Sparreboom, M., 1986. Courtship in newts of the genus Triturus and Paramesotriton. In: Z. RočEK ed., Studies in herpetology. Proceedings of the European Herpetological Meeting (3rd Ordinary General Meeting of the Societas Europaea Herpetologica) Prague 1985: 529-533 (Charles University, Prague).

Verrell, P. A., 1984. Sexual interference and sexual defense in the Smooth Newt, Triturus vulgaris (Amphibia: Urodela: Salamandridae). Z. Tierpsychol., 66: 242-254.

Wambreuse, P. \& V. Bels, 1984. Analyse qualitative et quantitative de la parade sexuelle du Triton palmé Triturus helveticus (Razoumowsky, 1798). Cahiers d'Ethologie appliquée, 4: 193-218. 